\title{
Pattern recognition receptors in HIV transmission
}

\section{Annelies W. Mesman and Teunis B. Geijtenbeek*}

Department for Experimental Immunology, Academic Medical Center, University of Amsterdam, Amsterdam, Netherlands

\author{
Edited by: \\ Annapurna Vyakarnam, King's College \\ London, UK \\ Reviewed by: \\ Sarah Rowland-Jones, Weatherall \\ Institute of Molecular Medicine, John \\ Radcliffe Hospital, UK \\ Annapurna Vyakarnam, King's College \\ London, UK

\section{${ }^{*}$ Correspondence:} \\ Teunis B. Geijtenbeek, Department \\ for Experimental Immunology, \\ Academic Medical Center, University \\ of Amsterdam, Meibergdreef 9, 1105 \\ AZ Amsterdam, Netherlands. \\ e-mail: t.b.geijtenbeek@amc.uva.nl
}

Dendritic cells (DCs), Langerhans cells (LCs), and macrophages are innate immune cells that reside in genital and intestinal mucosal tissues susceptible to HIV-1 infection. These innate cells play distinct roles in initiation of HIV-1 infection and induction of anti-viral immunity. DCs are potent migratory cells that capture HIV-1 and transfer virus to $\mathrm{CD} 4^{+} \mathrm{T}$ cells in the lymph nodes, whereas LCs have a protective anti-viral function, and macrophages function as viral reservoirs since they produce viruses over prolonged times. These differences are due to the different immune functions of these cells partly dependent on the expression of specific pattern recognition receptors. Expression ofToll-like receptors, C-type lectin receptors, and cell-specific machinery for antigen uptake and processing strongly influence the outcome of virus interactions.

\section{Keywords: innate immunity, HIV transmission}

\section{INTRODUCTION}

The innate immune system forms the first line of defense against invading pathogens. Innate immune cells, such as dendritic cells (DCs), Langerhans cells (LCs), and macrophages reside within mucosal tissues. The main route of HIV-1 infection is sexual transmission and therefore the interplay between the virus and innate immune cells within the mucosa plays a crucial role in initiating an effective immune response as well as dissemination of the virus. HIV-1 infects CD4 ${ }^{+} \mathrm{T}$ cells within the secondary lymph nodes and innate immune cells are thought to be involved in transmitting virus to these T cells. HIV-1 infects cells upon interaction of viral envelope protein gp120 with CD4 and co-receptors, such as CCR5 or CXCR4, which initiate fusion of the virus with the cell membrane. Besides $\mathrm{CD} 4^{+} \mathrm{T}$ cells, DCs, LCs, and macrophages also express CD4 and CCR5. The exact roles of the different innate immune cells upon virus entry into the host, and whether the interactions with the virus by these cells are beneficial to host or virus, are not yet clear. However, their function in HIV-1 transmission is strongly influenced by expression of pattern recognition receptors (PRRs) including C-type lectin receptors (CLRs). Extensive research during the last decade has given us more insight into the different events that follow upon HIV-1 binding to innate immune cells, which are related to cell-specific functions, receptor expression, and receptor signaling.

\section{MUCOSAL ENTRY}

Over $80 \%$ of new HIV-1 infections globally occur via sexual transmission (UNAIDS, 2010). The first barrier that HIV-1 encounters is the epithelium of the genital and intestinal tract. Epithelial cells do not express CD4 but these cells can be involved in HIV-1 transmigration albeit not efficiently. Syndecans, a specific class of heparin-sulfate proteoglycan, mediate internalization of HIV1 through gp120 (Bobardt et al., 2007) and gp120-epithelial cell interaction decreases transepithelial resistance (Nazli et al., 2010). The latter occurs via induction of inflammatory cytokines and subsequent downregulation of junction genes, which facilitate transport of HIV-1 across the epithelial barrier. However, DCs or LCs are proposed as initial target cells of HIV-1 that mediate transfer of the virus to $\mathrm{CD} 4^{+} \mathrm{T}$ cells in the draining lymph nodes, which is supported by both ex vivo and in vivo studies, (Spira et al., 1996; Hu et al., 2000; Gupta et al., 2002; Veazey et al., 2003; Hladik et al., 2007).

\section{MUCOSAL INNATE IMMUNE CELLS}

Innate immune cells residing in the mucosa express PRRs including Toll-like receptors (TLRs) and CLRs to sense pathogens and pathogenic-derived structures. Viral internalization takes place via receptor-mediated clathrin- or caveolin-dependent endocytosis, receptor-mediated phagocytosis, or through receptorindependent macropinocytosis (Trombetta and Mellman, 2005; Burgdorf and Kurts, 2008). Subsequently, uptake leads to pathogen degradation and antigen presentation to $\mathrm{T}$ cells to initiate immune responses (Banchereau et al., 2000; Romani et al., 2010). In addition, recognition of pathogenic structures by PRRs causes activation and maturation of the cells. Maturation leads to upregulation of costimulatory molecules to effectively present antigens and activate $T$ cells. PRR signaling is not only required for maturation of the cells, but also induces a pathogen-tailored cytokine program that shapes specific immunity through $\mathrm{T}$ helper cell polarization (Banchereau et al., 2000). The extent to which maturation and activation is induced by HIV-1 is controversial. Reports on LC and DC maturation in response to HIV-1, or to other stimuli after HIV-1 exposure are contradicting, and results might be influenced by virus and cell preparations (Granelli-Piperno et al., 2004; Smed-Sorensen et al., 2004; Harman et al., 2006). Understanding of immune activation in the early events of HIV-1 infection is crucial, since activation, and maturation by HIV-1 or co-infections affects not only viral uptake and transmission, but also induction of adaptive immune responses and the presence of immune cells in the mucosa (Patterson et al., 2002; Bafica et al., 2004; 
Turville et al., 2004). Although it is unclear how direct activation by HIV-1 occurs, HIV-1 modulates adaptive immunity induced by other stimuli through interactions with DC-SIGN (Gringhuis et al., 2009).

In the female genital tract, mucosal tissue consists of a single layer of endocervical columnar epithelium or squamous epithelium of vagina and ectocervix. Although some studies report slightly different expression patterns of widely used markers, in general LCs - defined by expression of CDla and Langerin are present within the epithelium. Intraepithelial and beneath this layer in the submucosa, CD11c+ DCs, CD68+ macrophages, and $\mathrm{CD}^{+}{ }^{+} \mathrm{T}$ cells, are localized (Geijtenbeek et al., 2000; Hladik et al., 2007; Hirbod et al., 2009, 2011). Also in the intestinal tract, foreskin, and rectum, DC, LCs, and macrophages are present (Geijtenbeek et al., 2000; Patterson et al., 2002; Gurney et al., 2005; Ribeiro Dos Santos et al., 2011).

Dendritic cells, LCs, and macrophages have their specific function in the immune system. Macrophages continually display phagocytic activity and are prone to initiate local inflammation and persist in the tissue (Cassol et al., 2010). DCs on the other hand are equipped to rapidly migrate to the lymph nodes, and therefore have a bridging function between innate and adaptive immunity (Banchereau et al., 2000). LCs belong to the DC family and are thought to have an important function to maintain mucosal homeostasis (von Bubnoff et al., 2004; Chu et al., 2011). It is not clear whether LCs are as efficient in their antigen presenting functions as DC, since compared to conventional DCs, these cells have slower migratory capacities (Villadangos and Heath, 2005; Romani et al., 2010). Innate immune cells express CD4 and coreceptors, required for HIV-1 infection, as well as PRRs that sense viruses to initiate immune activation. These include TLRs to recognize viral nucleic acids and CLRs that besides sensing can also function as viral attachment receptors. Furthermore, besides CLRs, syndecans can also function as attachments receptor on innate immune cells (Saphire et al., 2001; de Witte et al., 2007a).

\section{PATTERN RECOGNITION RECEPTORS IN HIV-1 INFECTION}

Infected DCs, LCs, and macrophages have been observed shortly after sexual transmission (Spira et al., 1996; Collins et al., 2000; Hu et al., 2000; Patterson et al., 2002; Hladik et al., 2007), strongly suggesting that these innate immune cells are an initial target for HIV-1. In addition to entry receptors, infection of innate immune cells is influenced by expression of CLRs and TLRs via internalization and/or immune activation. Whereas fusion of HIV-1 depends on CD4 and coreceptors, internalization and uptake depends on CLRs. CLRs recognize glycosylated structures via conserved carbohydrate recognition domains (Cambi et al., 2005; Robinson et al., 2006) and the heavily glycosylated HIV-1 envelope glycoprotein gp120 is recognized by mannose-specific CLRs such as dendritic cell specific ICAM-3 grabbing non-integrin (DC-SIGN), LC-specific Langerin, and the mannose receptor (MR). A recent study suggests that gp120 is also recognized by DC Immunoreceptor (DCIR) but the carbohydrate structures recognized are not clear (Lambert et al., 2008). MR, DC-SIGN, and DCIR are expressed by specific macrophage and DC subsets (Turville et al., 2001, 2002; Lambert et al., 2008). Langerin is specific for LCs in humans (Valladeau et al., 1999). In mice, a Langerin expressing
DC subset has been identified, but its human homolog is not yet clear (Ginhoux et al., 2007) DC-SIGN, MR, and DCIR promote infection of innate immune cells but also transmission of HIV-1 to target $\mathrm{T}$ cells, while Langerin prevents infection through viral degradation (de Witte et al., 2008; van der Vlist et al., 2011). Therefore, expression of specific CLRs influences infection and HIV-1 internalization and at least partly determines the role of the innate immune cells in HIV-1 transmission.

Toll-like receptors comprise a family of plasma membrane and intracellular receptors. DCs and macrophages express a variety of TLRs (TLR1-8 and TLR10) to recognize bacterial and viral ligands (Kawai and Akira, 2011). Regarding HIV-1 recognition, HIV-1derived ssRNA is sensed by TLR7/8 (Heil et al., 2004), although a recent study shows that infection of DCs triggers TLR8 but not TLR7 (Gringhuis et al., 2010), suggesting that TLR8 might be more important in HIV-1 sensing. LCs mainly express TLRs for recognition of viral products and lack TLR4. However, expression of TLR7/8 by LCs is debated (Flacher et al., 2006; van der Aar et al., 2007). Most TLRs are constitutively expressed in the genital mucosa but expression is tightly regulated, and both TLR2 and TLR4 seem restricted to the upper parts of the tract (Pioli et al., 2004; Fazeli et al., 2005), suggesting that the site of mucosal transmission might influence immune activation. TLR activation leads to innate immune activation as well as adaptive immune responses. Antiviral TLRs specifically induce production of interferons that interfere with virus replication (Bowie and Unterholzner, 2008; Ogawa et al., 2009). As a consequence, TLR4 signaling in DCs and macrophages decreases infection of the cells (Kornbluth et al., 1989; Thibault et al., 2009; Wang et al., 2011), whereas signaling via TLRs has also been shown to promote HIV-1 infection in innate cells directly through signaling and promoting HIV-1 transcription or indirect through cytokine induction (Table 1; Bafica et al., 2004; Gringhuis et al., 2010; Herbein et al., 2010). However, the effect of TLR triggering on HIV-1 infection as well as the effect of infection on PRR function depends on the innate immune cell a well as the receptor. Thus, TLR expression on innate immune cells and pathogen-driven TLR activation in the mucosa affects HIV-1 transmission.

Besides CLRs and TLRs, cytoplasmic tripartite motifcontaining protein $5 \alpha$ (TRIM5 $\alpha$ ) acts as a PRR in myeloid cells. Retrovirus restriction factor TRIM5 $\alpha$ interacts with the HIV-1 capsid (Stremlau et al., 2004), accelerates uncoating of the virus and thereby prevents reverse-transcriptase (Stremlau et al., 2006). However, recently another function of TRIM $5 \alpha$ was described. HIV-1 capsid interaction with TRIM5 $\alpha$ generates ubiquitin chains that activate the TAK1 kinase complex and subsequenlty activate transcription factors NFKB and AP-1 (Pertel et al., 2011). Notably, TRIM $5 \alpha$ constitutively promotes innate immune signaling and sensing of retroviral capsids increases inflammatory gene transcription as well as retroviral restriction activity. Thus, TRIM $5 \alpha$ can act as a PRR and activate innate signaling in response to retroviral infection. The importance in HIV-1 infection and sensing needs to be investigated.

\section{LANGERHANS CELLS}

Due to their localization in the epithelium LCs are the first cells to encounter HIV-1 and therefore regarded as "primary gatekeepers" 
Table 1 | Examples of PRR-mediated effects on HIV infection in innate immune cells.

\begin{tabular}{|c|c|c|c|c|}
\hline Pathogen & Cell type & Effect on HIV infection & Receptors involved & References \\
\hline Mycobacterium tuberculosis & Macrophage & Increased replication, transmission, LTR activation & TLR2 & $\begin{array}{l}\text { Zhang et al. (1995), } \\
\text { Mancino et al. (1997) }\end{array}$ \\
\hline \multirow[t]{2}{*}{ Neisseria gonorrhoeae } & $\mathrm{DC}$ & Increased entry/replication & TLR2 & Zhang et al. (2005) \\
\hline & $\mathrm{LC}$ & Increased transmission & TLR1/2 & de Jong et al. (2008) \\
\hline Lactobacillus acidophilus & Macrophage & Increased infection & TLR2 & Ahmed et al. (2010) \\
\hline Leishmania donovani & Macrophage & Increased replication & TLR2 & Bernier et al. (1995) \\
\hline Candida albicans & $\mathrm{LC}$ & Increased transmission & $\mathrm{TLR} 1 / 2$ & de Jong et al. (2008) \\
\hline Escherichia coli & Macrophage & Reduced infection & TLR4 & Ahmed et al. (2010) \\
\hline \multirow[t]{2}{*}{ Staphylococcus aureus } & $\mathrm{DC}$ & Reduced infection & TLR4 & Ogawa et al. (2009) \\
\hline & LC & Increased infection & & \\
\hline \multirow[t]{2}{*}{ Salmonella typhimurium } & $\mathrm{DC}$ & Reduced infection & TLR4 & Ogawa et al. (2009) \\
\hline & LC & No effect & & \\
\hline Herpes simplex virus-2 & LC & Increased infection, transmission & Langerin & de Jong et al. (2010) \\
\hline \multicolumn{5}{|l|}{ LIGANDS } \\
\hline Pam3Cysk4, LTA & $\mathrm{DC}$ & Increased transmission & TLR2 & Thibault et al. (2009) \\
\hline LPS & DC, macrophage & Reduced infection/transmission, replication & TLR4 & $\begin{array}{l}\text { Kornbluth et al. } \\
\text { (1989), Thibault et al. } \\
\text { (2009), Wang et al. } \\
\text { (2011) }\end{array}$ \\
\hline Interferon & Macrophage & Reduced infection, replication & TLR3 & $\begin{array}{l}\text { Kornbluth et al. } \\
\text { (1989), Ahmed et al. } \\
\text { (2010) }\end{array}$ \\
\hline
\end{tabular}

(Kawamura et al., 2003). Infected mucosal LCs have been identified as early target cells in foreskin and vagina (Hu et al., 2000; Patterson et al., 2002; Hladik et al., 2007). However, although HIV1 is very rapidly internalized by these cells, infection of immature LCs is very inefficient (de Witte et al., 2007b; Hladik et al., 2007; Ballweber et al., 2011). LCs bind gp120 predominantly through the CLR Langerin (Turville et al., 2002; de Witte et al., 2007b). Notably, HIV-1 virions captured by Langerin are directed to birbeck granules for degradation (de Witte et al., 2007b). As a consequence, immature LCs do not promote T cell infection (de Witte et al., 2007b; Fahrbach et al., 2007) (Figure 1). The outcome of LC interaction with HIV-1 is mainly determined by their activation status. In contrast to immature LCs, activated LCs transmit HIV-1 to T cells (de Witte et al., 2007b; Fahrbach et al., 2007). Transmission by LCs to T cells is considered to be dependent on LC infection, since infected LCs effectively transmit HIV-1 to T cells (Reece et al., 1998; Kawamura et al., 2000; Sivard et al., 2004; de Jong et al., 2008), although it has been reported that LCs are able to transfer virus to T cells independent of infection (Hladik et al., 2007; de Jong et al., 2008; Ballweber et al., 2011).

Langerhans cell activation, and subsequently enhanced infection as well as transmission is induced by co-infections, and explains partly the increased risk of HIV-1 infection in persons carrying other sexually transmitted diseases. Gram + bacteria, Candida albicans, and Neisseria gonorrhea enhance capture, replication, and transmission via induction of TNF- $\alpha$ or modulation of the interferon response as a result of TLR1/TLR2 binding (de Jong et al., 2008; Ogawa et al., 2009). On another level, Herpes Simplex Virus-2 interferes with the protective role of Langerin by competing for receptor binding and decreasing expression levels (de Jong et al., 2010). Thus, immune activation is a critical determinant in susceptibility to HIV-1.

Immature LCs have a protective role in infection, which drastically changes upon cell maturation as mature LCs effectively transfer HIV-1. Because of the striking differences between immature and activated LCs in virus degradation and transmission respectively, LCs play a pivotal role in HIV-1 transmission.

\section{DENDRITIC CELLS}

Infected DCs and DC-T cell conjugates have been observed soon after infection in vaginal and rectal tissue. Within hours upon exposure, HIV-1 infected cells were detected in draining lymph nodes (Spira et al., 1996; Hu et al., 2000; Ribeiro Dos Santos et al., 2011). DCs are the most potent APCs, capable of rapid migration to the lymph nodes to present antigens to $\mathrm{T}$ cells and therefore it has been proposed that DCs migrate to the lymph node where they transfer HIV-1 to T cells (Figure 1).

Dendritic cells binding and internalization of HIV-1 is mainly facilitated by DC-SIGN and DC-SIGN-bound virions remain infectious for days allowing transmission independent of infection, supporting a role for DCs in viral transport (Geijtenbeek et al., 2000; Kwon et al., 2002). However, DCs are also infected by HIV-1. The importance of direct infection compared to HIV-1 capture depends on the time scale. Whereas DC-SIGN-captured virus can be transmitted for several days, Turville et al. (2004) have shown that after two days DC infection becomes more important in HIV-1 transmission. Furthermore, DC infection might lead to the formation of HIV-1 reservoirs as has been shown for macrophages (Coleman and Wu, 2009). Both immature and mature DCs internalize HIV-1 and facilitate trans-infection. 


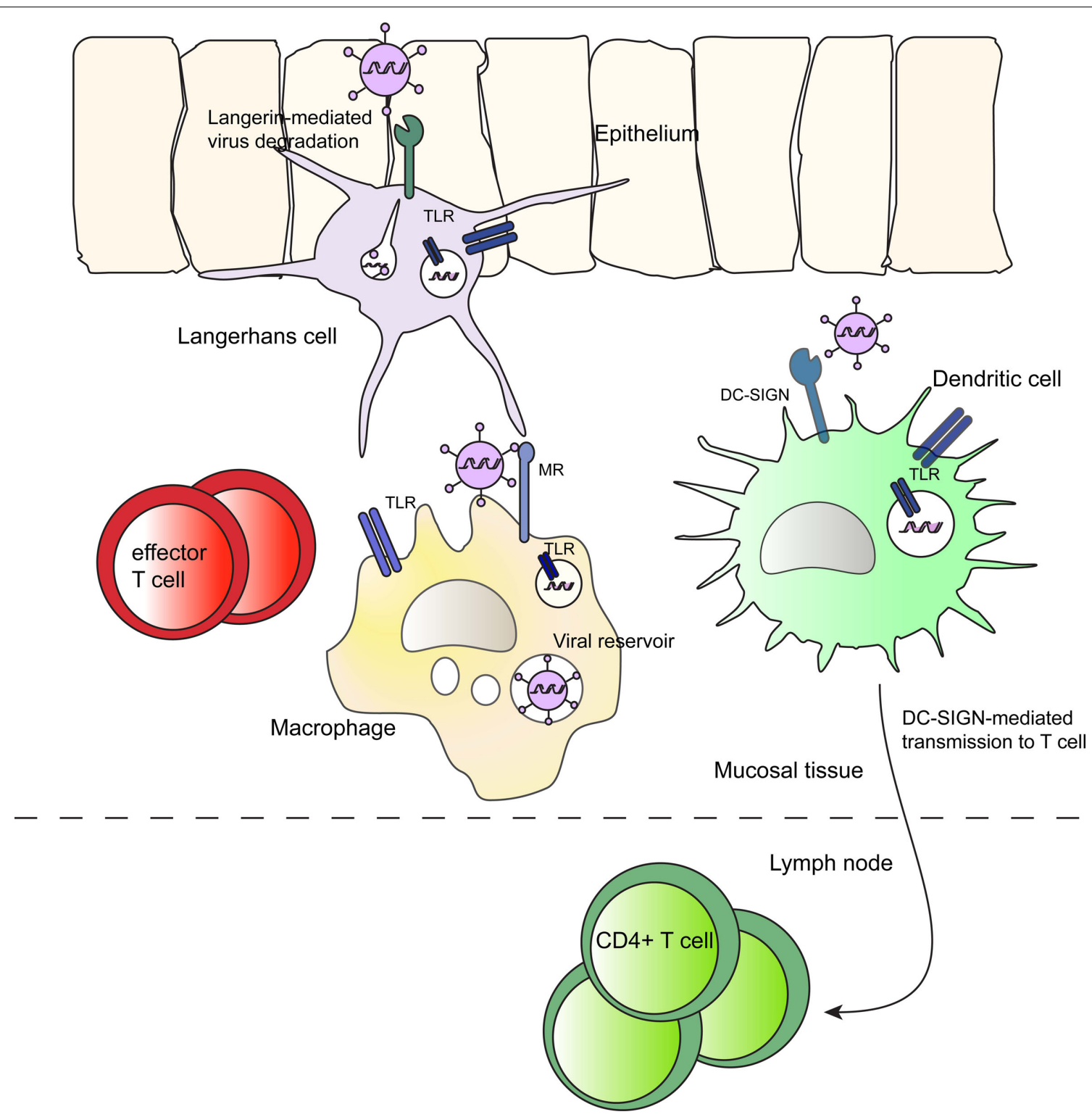

FIGURE 1 | The role of innate immune cells in HIV-1 infection largely depends on PRR expression. Innate immune cells reside in mucosal and submucosal tissue. DCs internalize HIV-1 and migrate to the lymph node to transfer virus to $\mathrm{CD}^{+}{ }^{+} \mathrm{T}$ cells and this process is mediated by DC-SIGN.

Immature LCs express Langerin, which promotes viral degradation in Birbeck granules. Macrophages take up HIV-1 via MR, but are most important as an HIV-1 reservoir. All three innate immune cells in addition express various TLRs on the cell surface and in endosomes to sense pathogenic-derived antigens. Subsequent TLR signaling influences HIV-1 infection and immune activation.
Immature DCs capture HIV-1 more efficiently and infection is higher, whereas mature DCs most efficiently transfer virus to $\mathrm{T}$ cells (Turville et al., 2004; Yu et al., 2008). In addition to promoting viral transfer, virus capture through DC-SIGN favors infection of DCs since DC-SIGN colocalizes with CD4 and CCR5 and thereby promotes binding to the fusion receptors (Lee et al., 2001). Strikingly, DC-SIGN signaling is also crucial for initiation of HIV-1 transcription. Notably, other pathogens that interact with DCSIGN also induce DC-SIGN signaling and thereby enhance HIV-1 transcription (Gringhuis et al., 2010). In addition to internalization, DC-SIGN ligation and T cell contact induce formation of a virological synapse to which HIV-1-containing vesicles are rapidly recruited for transfer (McDonald et al., 2003; Arrighi et al., 2004; Turville et al., 2004). Although the virological synapse is reminiscent of immunological synapse it forms independent of antigen presentation or MHC-TCR interactions (Piguet and Sattentau, 2004). Different models have been proposed regarding how HIV1 in DCs is protected from degradation and whether the virus is internalized upon DC-SIGN binding and if so, to what compartments it is directed to enable transfer to $\mathrm{T}$ cells. It has been proposed that the majority of transferred virus is retained surfacebound (Cavrois et al., 2007), but most studies support a model in 
which HIV-1 is internalized into compartments that do not belong to the classical endosomal/lysosomal pathway. Here the virus is protected from lysosomes and neutralizing antibodies (Kwon et al., 2002; McDonald et al., 2003; Turville et al., 2004). Slightly different models have been proposed where HIV-1 induces specific surface-accessible CD81+ vesicles, contiguous with the plasma membrane to protect the virus from lysosomal degradation (Yu et al., 2008). Furthermore, it has been suggested that HIV-1 makes use of the exosome pathway to be secreted for transmission (Wiley and Gummuluru, 2006), which is supported by suggestion that HIV-1 particles contain similar proteins and lipids as exosomes (Gould et al., 2003). Exploitation of the exosome pathway by HIV-1 for transfer to $\mathrm{T}$ cells has also been proposed to occur independent of gp120 and CLRs (Izquierdo-Useros et al., 2009). Notably, the exosome pathways contain tetraspanin proteins, such as CD81, also found in HIV-1-containing multivesicular bodies, which might be involved in exosome production and might explain presence of HIV-1 in exosomes.

Over the last few years, some underlying mechanisms of DCSIGN signaling, and how these events affect transmission, have become clear. DC-SIGN-HIV-1 interaction leads to recruitment of Guanine exchange factor (GEF) LARG and RhoA to the DCSIGN signalosome and in turn activation of kinase Raf-1. Through Raf- 1 activation, DCs shape adaptive immune responses to HIV1 (Gringhuis et al., 2009). However, Raf-1 activation by HIV-1 is also required for HIV-1 replication in DCs (Gringhuis et al., 2010). Multiple studies focused on how proteins involved in DCSIGN signaling affect internalization and synapse formation by influencing motility or arrangement of the cytoskeleton. Specifically, DC-SIGN-mediated activation of LARG induces cytoskeleton rearrangements that are important for the formation of the virological synapse (Hodges et al., 2007), whereas DC-SIGN activation of Rho-GTPase cdc42 is crucial for the induction of membrane extensions and recruitment of virus to the synapse (Nikolic et al., 2011). Scaffolding protein LSP1, part of the DC-SIGN signalosome, is proposed to mediate transfer to the proteasome for degradation and thus has a negative role for transmission (Smith et al., 2007). LSP1 is involved in chemotaxis of DCs, but LSP1induced cell motility is also facilitated by gp 120-CCR5 interaction (Anand et al., 2009), indicating multiple HIV-1 receptors might be involved in transmission events.

DC-SIGN is the most studied CLR regarding HIV-1 due to its special role in promoting infection and transmission, but other CLRs expressed by DCs, including DCIR and MR, have been demonstrated to interact with HIV-1. Although not much known about the function of DCIR in DCs, and no specific ligands have been described, binding of HIV-1 to DCIR enhances infection of DCs and transmission tot T cells (Lambert et al., 2008). DCIR is the only CLR expressed on DCs containing an intracellular immunoreceptor tyrosine-based inhibitory motif (ITIM), and this intracellular part is required for its effect on infection (Lambert et al., 2008, 2011). MR has been suggested to internalize and traffic virus to endosomes and lysosomes upon binding gp120 (Turville et al., 2004). Thus MR interaction might promote degradation and MHCII Ag presentation in DCs. Capture via DC-SIGN has also been proposed to promote antigen presentation, both in the context of MHCI, following fusion and proteosomal degradation, or MHCII via a pathway independent of productive infection (Moris et al., 2004, 2006). Thus, DC-SIGN, but also other CLRs are involved in uptake of HIV-1 leading to transmission or antigen presentation.

Similar to macrophages, involvement of TLRs can be detrimental for DC infection. Although both TLR2 and TLR4 ligands enhance entry, only TLR2 ligands, such as Neisseria gonorrhoeae, enhance infection, and transmission of DCs through signaling (Zhang et al., 2005), whereas TLR4 triggering decreases due to interferon induction and TLR5 TLR7/9 have no effect (Thibault et al., 2009). Strikingly, although HIV-1 RNA efficiently activates plasmacytoid DCs through TLR7 and TLR9, it does not activate conventional DCs through TLR7 and TLR8 (Beignon et al., 2005). Recent data show that TLR8 triggering and NF- $\kappa \mathrm{B}$ activation is required for HIV-1 infection in DCs (Gringhuis et al., 2010), suggesting that HIV-1 additional signals are required for activation in DCs.

Dendritic cells express several CLRs that promote infection and viral transfer to $\mathrm{T}$ cells. Virus interaction with DC-SIGN induces internalization into specific vesicles and formation of a virological synapse to facilitate transmission. DCs therefore have an important role in virus dissemination.

\section{MACROPHAGES}

Infected macrophages are detected in the female genital tract soon after exposure to HIV-1 (Collins et al., 2000). However, compared to DCs and LCs, macrophages do not seem to be important in initiation of infection, since they do not have a clear protective or HIV-1 transmitting function.

Uptake of HIV-1 by macrophages can occur dependent or independent of CLR binding. Uptake has been shown to occur by macropinocytosis, leading to degradation of many particles in lysosomes (Marechal et al., 2001). An additional receptormediated phagocytosis pathway was described, which is induced by interaction with MR, accounting for a large part of HIV-1 binding (Nguyen and Hildreth, 2003). Virus-MR interactions lead to degradation via clathrin-dependent lysosomal pathway and antigen presentation whereas the interactions do not promote infection (Trujillo et al., 2007). Besides its role in antigen presentation, MR is also involved in HIV-1 transmission (Nguyen and Hildreth, 2003). In contrast to DC-SIGN, MR-mediated uptake does not lead to protection of HIV-1, supporting a function in antigen degradation and presentation similar to its role in DCs (Nguyen and Hildreth, 2003). Recently a novel uptake route, an alternative macropinocytosis pathway, has been described. This entry route, independent of caveolin, clathrin and PI3K, but dependent on actin, Rho family GTPases, and dynamin leads to infection by HIV-1. How this pathway is induced and whether MR is involved is not known (Carter et al., 2010).

Since macrophages do not migrate after activation, their function in initial dissemination of HIV-1 to T cells is limited. However infected macrophages are an important HIV-1 reservoir, and very capable of infecting $\mathrm{T}$ cells over a prolonged time period. Within multivesicular bodies, de novo produced virus can persist and retain infectious for weeks to infect $\mathrm{T}$ cells (Carr et al., 1999; Sharova et al., 2005) (Figure 1). Stored virus from the CD81+ compartments can be transmitted in a regulated way to $\mathrm{T}$ cells 
via transient synapse formation (Deneka et al., 2007; Groot et al., 2008). Similarly, the exosome pathway might be involved, since exosomes are derived from multivesicular bodies (Denzer et al., 2000). Thus, macrophages as reservoirs might facilitate infection of other cells including T cells but also DCs in mucosal tissues. It is however unclear whether a reservoir role for macrophages is relevant in mucosal tissue direct after sexual transmission since the replication capacity of transmitted/founder virus in macrophages is lower compared to HIV strains used in most in vitro studies (Ochsenbauer et al., 2012).

Macrophage activation by TLR ligands influences HIV-1 infection. Interferon-inducing ligands or pathogens that trigger TLR3 TLR4, TLR7/8 have been shown to impair replication (Kornbluth et al., 1989; Wang et al., 2011), while infection with pathogens that trigger TLR2 increase virus production (e.g., M. tuberculosis) or do not affect infection (Mancino et al., 1997; Bafica et al., 2003; Ahmed et al., 2010). This suggests that depending on the pathogen, co-infections increase, or protect from HIV-1 replication in macrophages in the mucosa.

Macrophages seem to function as reservoirs for HIV-1 and therefore are able to transmit virus to $\mathrm{T}$ cells or DCs residing in mucosal tissues. As opposed to DCs, HIV-1 capture leads also to degradation and Ag presentation and therefore HIV-1 infection of macrophages is a major factor in their role as HIV-1 reservoir.

\section{FUTURE DIRECTIONS AND CONCLUDING REMARIKS}

Innate immune cells reside in the tissues where HIV-1 enters the body. Their capacity to capture and digest pathogens, and subsequently interact with $\mathrm{T}$ cells, contributes to mechanisms of viral transfer to $\mathrm{CD}_{4}{ }^{+} \mathrm{T}$ cells. Cell-specific CLRs mediate HIV-1 degradation, antigen processing, or in the case of DC-SIGN protection of HIV-1. Multiple HIV-1 binding CLRs and PRR-induced pathways influence dissemination or degradation by innate immune cells and dominance of one particular pathway will depend on activation status of the innate immune cell. Our knowledge of mechanisms underlying these events has improved greatly, but

\section{REFERENCES}

Ahmed, N., Hayashi, T., Hasegawa, A., Furukawa, H., Okamura, N., Chida, T., Masuda, T., and Kannagi, M. (2010). Suppression of human immunodeficiency virus type 1 replication in macrophages by commensal bacteria preferentially stimulating Toll-like receptor 4. J. Gen. Virol. 91, 2804-2813.

Anand, A. R., Prasad, A., Bradley, R. R., Deol, Y. S., Nagaraja, T., Ren, X., Terwilliger, E. F., and Ganju, R. K. (2009). HIV-1 gp120-induced migration of dendritic cells is regulated by a novel kinase cascade involving Pyk2, p38 MAP kinase, and LSP1. Blood 114, 3588-3600.

Arrighi, J. F., Pion, M., Garcia, E., Escola, J. M., Van Kooyk, Y., Geijtenbeek, T. B., and Piguet, V. (2004). DC-SIGN-mediated infectious synapse formation enhances
X4 HIV-1 transmission from dendritic cells to T cells. J. Exp. Med. 200, 1279-1288.

Bafica, A., Scanga, C. A., Schito, M., Chaussabel, D., and Sher, A. (2004). Influence of coinfecting pathogens on HIV expression: evidence for a role of Toll-like receptors. $J$. Immunol. 172, 7229-7234.

Bafica, A., Scanga, C. A., Schito, M. L., Hieny, S., and Sher, A. (2003). Cutting edge: in vivo induction of integrated HIV-1 expression by mycobacteria is critically dependent on Toll-like receptor 2. J. Immunol. 171, 1123-1127.

Ballweber, L., Robinson, B., Kreger, A., Fialkow, M., Lentz, G., Mcelrath, M. J., and Hladik, F. (2011). Vaginal langerhans cells nonproductively transporting HIV-1 mediate infection of T cells. J. Virol. 85, 13443-13447.

some important questions remain and might be crucial to answer before effective prevention methods can be developed. For example, the reason why sexual transmission of HIV-1 is restricted to R5 strains remains to be elucidated. DCs are infected with and transmit both X4 and R5 strains, and mucosal T cells express both coreceptors (Geijtenbeek et al., 2000; Kwon et al., 2002; Veazey et al., 2003). LCs are primarily infected with R5 virus, although $\mathrm{X} 4$ transmission has been observed as well, indicating the need for additional research on this topic (Sivard et al., 2004; de Jong and Geijtenbeek, 2009). Secondly, non-human primate studies provide a valuable tool for in vivo pathogenesis studies and drug testing. Although the SIV infection in macaques is similar to HIV infection in humans, differences in disease progression and host factors must be kept in mind (Sina et al., 2010; Van Rompay, 2012). The importance of the described mechanisms in vivo is another point of debate. Contradicting findings can be explained by the use of different experimental setups, ex vivo models or use of specific differentiation methods for DCs, LCs, or macrophages. In addition, the in vivo plasticity of the phenotype and function of innate immune cells makes it difficult to translate all results to the in vivo situation (Geissmann et al., 2010; Galli et al., 2011). Still, an important role for CLR in HIV-1 transmission in vivo is illustrated by a recent finding that expression of Langerin, DC-SIGN, and MR, but not HLA-DR, is significantly higher in mucosa of a highrisk population (Hirbod et al., 2009). But whether this increased expression is protective or detrimental for the host cannot be answered.

During the last years, the focus of HIV-1 transmission research has shifted toward a more immunological approach. Elucidating intracellular signaling and cellular effects following HIV-1 interaction will contribute to a better understanding of the first events upon sexual transmission.

\section{ACKNOWLEDGMENTS}

We would like to thank the Host Defense group for their critical input. A.W. Mesman is supported by ZonMW (grant \#91208012).

Banchereau, J., Briere, F., Caux, C., Davoust, J., Lebecque, S., Liu, Y. J., Pulendran, B., and Palucka, K. (2000). Immunobiology of dendritic cells. Annu. Rev. Immunol. 18, 767-811.

Beignon, A. S., Mckenna, K., Skoberne, M., Manches, O., Dasilva, I., Kavanagh, D. G., Larsson, M., Gorelick, R. J., Lifson, J. D., and Bhardwaj, N. (2005). Endocytosis of HIV-1 activates plasmacytoid dendritic cells via Toll-like receptor-viral RNA interactions. J. Clin. Invest. 115, 3265-3275.

Bernier, R., Turco, S. J., Olivier, M., and Tremblay, M. (1995). Activation of human immunodeficiency virus type 1 in monocytoid cells by the protozoan parasite Leishmania donovani. J. Virol. 69, 7282-7285.

Bobardt, M. D., Chatterji, U., Selvarajah, S., Van Der Schueren, B., David,
G., Kahn, B., and Gallay, P. A. (2007). Cell-free human immunodeficiency virus type 1 transcytosis through primary genital epithelial cells. $J$. Virol. 81, 395-405.

Bowie, A. G., and Unterholzner, L. (2008). Viral evasion and subversion of pattern-recognition receptor signalling. Nat. Rev. Immunol. 8, 911-922.

Burgdorf, S., and Kurts, C. (2008). Endocytosis mechanisms and the cell biology of antigen presentation. Curr. Opin. Immunol. 20, 89-95.

Cambi, A., Koopman, M., and Figdor, C. G. (2005). How C-type lectins detect pathogens. Cell. Microbiol. 7, 481-488.

Carr, J. M., Hocking, H., Li, P., and Burrell, C. J. (1999). Rapid and efficient cell-to-cell transmission of human immunodeficiency virus infection from monocyte-derived 
macrophages to peripheral blood lymphocytes. Virology 265, 319-329.

Carter, G. C., Bernstone, L., Baskaran, D., and James, W. (2010). HIV-1 infects macrophages by exploiting an endocytic route dependent on dynamin, Racl and Pakl. Virology 409, 234-250.

Cassol, E., Cassetta, L., Alfano, M., and Poli, G. (2010). Macrophage polarization and HIV-1 infection. J. Leukoc. Biol. 87, 599-608.

Cavrois, M., Neidleman, J., Kreisberg, J. F., and Greene, W. C. (2007). In vitro derived dendritic cells trans-infect CD4 $\mathrm{T}$ cells primarily with surface-bound HIV-1 virions. PLoS Pathog. 3, e4. doi:10.1371/journal.ppat.0030004

Chu, C. C., Di Meglio, P., and Nestle, F. O. (2011). Harnessing dendritic cells in inflammatory skin diseases. Semin. Immunol. 23, 28-41.

Coleman, C. M., and Wu, L. (2009). HIV interactions with monocytes and dendritic cells: viral latency and reservoirs. Retrovirology 6, 51.

Collins, K. B., Patterson, B. K., Naus, G. J., Landers, D. V., and Gupta, P. (2000). Development of an in vitro organ culture model to study transmission of HIV-1 in the female genital tract. Nat. Med. 6, 475-479.

de Jong, M. A., De Witte, L., Oudhoff, M. J., Gringhuis, S. I., Gallay, P., and Geijtenbeek, T. B. (2008). TNF-alpha and TLR agonists increase susceptibility to HIV1 transmission by human Langerhans cells ex vivo. J. Clin. Invest. 118, 3440-3452.

de Jong, M. A., De Witte, L., Taylor, M. E., and Geijtenbeek, T. B. (2010). Herpes simplex virus type 2 enhances HIV-1 susceptibility by affecting Langerhans cell function. J. Immunol. 185, 1633-1641.

de Jong, M. A., and Geijtenbeek, T. B. (2009). Human immunodeficiency virus-1 acquisition in genital mucosa: langerhans cells as key-players. J. Intern. Med. 265, 18-28.

de Witte, L., Bobardt, M., Chatterji, U., Degeest, G., David, G., Geijtenbeek, T. B., and Gallay, P. (2007a). Syndecan-3 is a dendritic cell-specific attachment receptor for HIV-1. Proc. Natl. Acad. Sci. U.S.A. 104, 19464-19469.

de Witte, L., Nabatov, A., Pion, M., Fluitsma, D., De Jong, M. A., De Gruijl, T., Piguet, V., Van Kooyk, Y., and Geijtenbeek, T. B. (2007b). Langerin is a natural barrier to HIV1 transmission by Langerhans cells. Nat. Med. 13, 367-371. de Witte, L., Nabatov, A., and Geijtenbeek, T. B. (2008). Distinct roles for DC-SIGN+-dendritic cells and Langerhans cells in HIV-1 transmission. Trends. Mol. Med. 14, 12-19.

Deneka, M., Pelchen-Matthews, A., Byland, R., Ruiz-Mateos, E., and Marsh, M. (2007). In macrophages, HIV-1 assembles into an intracellular plasma membrane domain containing the tetraspanins CD81, CD9, and CD53. J. Cell Biol. 177, 329-341.

Denzer, K., Kleijmeer, M. J., Heijnen, H. F., Stoorvogel, W., and Geuze, H. J. (2000). Exosome: from internal vesicle of the multivesicular body to intercellular signaling device. J. Cell Sci. 113(Pt 19), 3365-3374.

Fahrbach, K. M., Barry, S. M., Ayehunie, S., Lamore, S., Klausner, M., and Hope, T. J. (2007). Activated CD34derived Langerhans cells mediate transinfection with human immunodeficiency virus. J. Virol. 81, 6858-6868.

Fazeli, A., Bruce, C., and Anumba, D. O. (2005). Characterization of Toll-like receptors in the female reproductive tract in humans. Hum. Reprod. 20, 1372-1378.

Flacher, V., Bouschbacher, M., Verronese, E., Massacrier, C., Sisirak, V., Berthier-Vergnes, O., De Saint-Vis, B., Caux, C., Dezutter-Dambuyant, C., Lebecque, S., and Valladeau, J. (2006). Human Langerhans cells express a specific TLR profile and differentially respond to viruses and Gram-positive bacteria. J. Immunol. 177, 7959-7967.

Galli, S. J., Borregaard, N., and Wynn, T. A. (2011). Phenotypic and functional plasticity of cells of innate immunity: macrophages, mast cells and neutrophils. Nat. Immunol. 12, 1035-1044.

Geijtenbeek, T. B., Kwon, D. S., Torensma, R., Van Vliet, S. J., Van Duijnhoven, G. C., Middel, J., Cornelissen, I. L., Nottet, H. S., Kewalramani, V. N., Littman, D. R., Figdor, C. G., and Van Kooyk, Y. (2000). DC-SIGN, a dendritic cellspecific HIV-1-binding protein that enhances trans-infection of $\mathrm{T}$ cells. Cell 100, 587-597.

Geissmann, F., Manz, M. G., Jung, S., Sieweke, M. H., Merad, M., and Ley, K. (2010). Development of monocytes, macrophages, and dendritic cells. Science 327, 656-661.

Ginhoux, F., Collin, M. P., Bogunovic, M., Abel, M., Leboeuf, M., Helft, J., Ochando, J., Kissenpfennig, A., Malissen, B., Grisotto, M., Snoeck, H., Randolph, G., and Merad, M. (2007). Blood-derived dermal Langerin+ dendritic cells survey the skin in the steady state. J. Exp. Med. 204, 3133-3146.

Gould, S. J., Booth, A. M., and Hildreth, J. E. (2003). The Trojan exosome hypothesis. Proc. Natl. Acad. Sci. U.S.A. 100, 10592-10597.

Granelli-Piperno, A., Golebiowska, A., Trumpfheller, C., Siegal, F. P., and Steinman, R. M. (2004). HIV1 -infected monocyte-derived dendritic cells do not undergo maturation but can elicit IL-10 production and T cell regulation. Proc. Natl. Acad. Sci. U.S.A. 101, 7669-7674.

Gringhuis, S. I., Den Dunnen, J., Litjens, M., Van Der Vlist, M., and Geijtenbeek, T. B. (2009). Carbohydratespecific signaling through the DCSIGN signalosome tailors immunity to Mycobacterium tuberculosis, HIV-1 and Helicobacter pylori. Nat. Immunol. 10, 1081-1088.

Gringhuis, S. I., Van Der Vlist, M. Van Den Berg, L. M., Den Dunnen, J., Litjens, M., and Geijtenbeek, T. B. (2010). HIV-1 exploits innate signaling by TLR8 and DCSIGN for productive infection of dendritic cells. Nat. Immunol. 11, 419-426.

Groot, F., Welsch, S., and Sattentau, Q. J. (2008). Efficient HIV-1 transmission from macrophages to $\mathrm{T}$ cells across transient virological synapses. Blood 111, 4660-4663.

Gupta, P., Collins, K. B., Ratner, D., Watkins, S., Naus, G. J., Landers, D. V., and Patterson, B. K. (2002). Memory $\mathrm{CD} 4(+) \mathrm{T}$ cells are the earliest detectable human immunodeficiency virus type 1 (HIV-1)-infected cells in the female genital mucosal tissue during HIV-1 transmission in an organ culture system. J. Virol. 76, 9868-9876.

Gurney, K. B., Elliott, J., Nassanian, H., Song, C., Soilleux, E., Mcgowan, I., Anton, P. A., and Lee, B. (2005). Binding and transfer of human immunodeficiency virus by DC-SIGN+ cells in human rectal mucosa. J. Virol. 79, 5762-5773.

Harman, A. N., Wilkinson, J., Bye, C. R., Bosnjak, L., Stern, J. L., Nicholle, M., Lai, J., and Cunningham, A. L. (2006). HIV induces maturation of monocyte-derived dendritic cells and Langerhans cells. J. Immunol. 177, 7103-7113.

Heil, F., Hemmi, H., Hochrein, H., Ampenberger, F., Kirschning, C., Akira, S., Lipford, G., Wagner, H., and Bauer, S. (2004). Species-specific recognition of single-stranded RNA via tolllike receptor 7 and 8 . Science 303, 1526-1529.

Herbein, G., Gras, G., Khan, K. A. and Abbas, W. (2010). Macrophage signaling in HIV-1 infection. Retrovirology 7,34

Hirbod, T., Kaldensjo, T., and Broliden, K. (2011). In situ distribution of HIV-binding CCR5 and C-type lectin receptors in the human endocervical mucosa. PLoS ONE 6, e25551. doi:10.1371/journal.pone.0025551

Hirbod, T., Kaldensjo, T., Lopalco, L., Klareskog, E., Andersson, S., UbertiFoppa, C., Ferrari, D., Manghi, M., Andersson, J., Lore, K., and Broliden, K. (2009). Abundant and superficial expression of C-type lectin receptors in ectocervix of women at risk of HIV infection. J. Acquir. Immune Defic. Syndr. 51, 239-247.

Hladik, F., Sakchalathorn, P., Ballweber, L., Lentz, G., Fialkow, M. Eschenbach, D., and Mcelrath, M. J. (2007). Initial events in establishing vaginal entry and infection by human immunodeficiency virus type-1. Immunity 26, 257-270.

Hodges, A., Sharrocks, K., Edelmann, M., Baban, D., Moris, A., Schwartz, O., Drakesmith, H., Davies, K., Kessler, B., Mcmichael, A., and Simmons, A. (2007). Activation of the lectin DC-SIGN induces an immature dendritic cell phenotype triggering Rho-GTPase activity required for HIV-1 replication. Nat. Immunol. 8, 569-577.

$\mathrm{Hu}, \mathrm{J} .$, Gardner, M. B., and Miller, C. J. (2000). Simian immunodeficiency virus rapidly penetrates the cervicovaginal mucosa after intravaginal inoculation and infects intraepithelial dendritic cells. J. Virol. 74, 6087-6095.

Izquierdo-Useros, N., Naranjo-Gomez, M., Archer, J., Hatch, S. C., Erkizia, I., Blanco, J., Borras, F. E., Puertas, M. C., Connor, J. H., Fernandez-Figueras, M. T., Moore, L., Clotet, B., Gummuluru, S., and Martinez-Picado, J. (2009). Capture and transfer of HIV-1 particles by mature dendritic cells converges with the exosome-dissemination pathway. Blood 113, 2732-2741.

Kawai, T., and Akira, S. (2011). Tolllike receptors and their crosstalk with other innate receptors in infection and immunity. Immunity 34, 637-650.

Kawamura, T., Cohen, S. S., Borris, D. L., Aquilino, E. A., Glushakova, S., Margolis, L. B., Orenstein, J. M., Offord, R. E., Neurath, A. R., and Blauvelt, A. (2000). Candidate microbicides block HIV-1 infection of human immature Langerhans cells within epithelial tissue explants. $J$. Exp. Med. 192, 1491-1500. 
Kawamura, T., Gulden, F. O., Sugaya, M., Mcnamara, D. T., Borris, D. L., Lederman, M. M., Orenstein, J. M., Zimmerman, P. A., and Blauvelt, A. (2003). R5 HIV productively infects Langerhans cells, and infection levels are regulated by compound CCR5 polymorphisms. Proc. Natl. Acad. Sci. U.S.A. 100, 8401-8406.

Kornbluth, R. S., Oh, P. S., Munis, J. R., Cleveland, P. H., and Richman, D. D. (1989). Interferons and bacterial lipopolysaccharide protect macrophages from productive infection by human immunodeficiency virus in vitro. J. Exp. Med. 169, 1137-1151.

Kwon, D. S., Gregorio, G., Bitton, N., Hendrickson, W. A., and Littman, D. R. (2002). DC-SIGN-mediated internalization of HIV is required for trans-enhancement of $\mathrm{T}$ cell infection. Immunity 16, 135-144.

Lambert, A. A., Barabe, F., Gilbert, C., and Tremblay, M. J. (2011). DCIRmediated enhancement of HIV1 infection requires the ITIMassociated signal transduction pathway. Blood 117, 6589-6599.

Lambert, A. A., Gilbert, C., Richard, M., Beaulieu, A. D., and Tremblay, M. J. (2008). The C-type lectin surface receptor DCIR acts as a new attachment factor for HIV-1 in dendritic cells and contributes to trans- and cis-infection pathways. Blood 112, 1299-1307.

Lee, B., Leslie, G., Soilleux, E., O'Doherty, U., Baik, S., Levroney, E., Flummerfelt, K., Swiggard, W., Coleman, N., Malim, M., and Doms, R. W. (2001). cis Expression of DC-SIGN allows for more efficient entry of human and simian immunodeficiency viruses via CD4 and a coreceptor. J. Virol. 75, 12028-12038.

Mancino, G., Placido, R., Bach, S., Mariani, F., Montesano, C., Ercoli, L., Zembala, M., and Colizzi, V. (1997). Infection of human monocytes with Mycobacterium tuberculosis enhances human immunodeficiency virus type 1 replication and transmission to T cells. J. Infect. Dis. 175, 1531-1535.

Marechal, V., Prevost, M. C., Petit, C., Perret, E., Heard, J. M., and Schwartz, O. (2001). Human immunodeficiency virus type 1 entry into macrophages mediated by macropinocytosis. J. Virol. 75, 11166-11177.

McDonald, D., Wu, L., Bohks, S. M., Kewalramani, V. N., Unutmaz, D., and Hope, T. J. (2003). Recruitment of HIV and its receptors to dendritic
cell-T cell junctions. Science 300, 1295-1297.

Moris, A., Nobile, C., Buseyne, F., Porrot, F., Abastado, J. P., and Schwartz, O. (2004). DC-SIGN promotes exogenous MHC-I-restricted HIV-1 antigen presentation. Blood 103, 2648-2654.

Moris, A., Pajot, A., Blanchet, F., GuivelBenhassine, F., Salcedo, M., and Schwartz, O. (2006). Dendritic cells and HIV-specific CD4+ T cells: HIV antigen presentation, $\mathrm{T}$-cell activation, and viral transfer. Blood 108, 1643-1651.

Nazli, A., Chan, O., Dobson-Belaire, W. N., Ouellet, M., Tremblay, M. J., Gray-Owen, S. D., Arsenault, A. L., and Kaushic, C. (2010). Exposure to HIV-1 directly impairs mucosal epithelial barrier integrity allowing microbial translocation. PLoS Pathog. 6, el000852. doi:10.1371/journal.ppat.1000852

Nguyen, D. G., and Hildreth, J. E. (2003). Involvement of macrophage mannose receptor in the binding and transmission of HIV by macrophages. Eur. J. Immunol. 33, 483-493.

Nikolic, D. S., Lehmann, M., Felts, R., Garcia, E., Blanchet, F. P., Subramaniam, S., and Piguet, V. (2011). HIV-1 activates Cdc42 and induces membrane extensions in immature dendritic cells to facilitate cell-tocell virus propagation. Blood 118, 4841-4852.

Ochsenbauer, C., Edmonds, T. G., Ding, H., Keele, B. F., Decker, J., Salazar, M. G., Salazar-Gonzalez, J. F., Shattock, R., Haynes, B. F., Shaw, G. M., Hahn, B. H., and Kappes, J. C. (2012). Generation of transmitted/founder HIV-1 infectious molecular clones and characterization of their replication capacity in CD4 Tlymphocytes and monocyte-derived macrophages. J. Virol. 5, 2715-2728. Ogawa, Y., Kawamura, T., Kimura, T., Ito, M., Blauvelt, A., and Shimada, S. (2009). Gram-positive bacteria enhance HIV-1 susceptibility in Langerhans cells, but not in dendritic cells, via Toll-like receptor activation. Blood 113, 5157-5166.

Patterson, B. K., Landay, A., Siegel, J. N., Flener, Z., Pessis, D., Chaviano, A., and Bailey, R. C. (2002). Susceptibility to human immunodeficiency virus-1 infection of human foreskin and cervical tissue grown in explant culture. Am. J. Pathol. 161, 867-873.

Pertel, T., Hausmann, S., Morger, D., Zuger, S., Guerra, J., Lascano, J., Reinhard, C., Santoni, F. A., Uchil, P. D., Chatel, L., Bisiaux, A., Albert, M. L., Strambio-De-Castillia, C.,
Mothes, W., Pizzato, M., Grutter, M. G., and Luban, J. (2011). TRIM5 is an innate immune sensor for the retrovirus capsid lattice. Nature 472, 361-365.

Piguet, V., and Sattentau, Q. (2004). Dangerous liaisons at the virological synapse. J. Clin. Invest. 114, 605-610.

Pioli, P. A., Amiel, E., Schaefer, T. M., Connolly, J. E., Wira, C. R., and Guyre, P. M. (2004). Differential expression of Toll-like receptors 2 and 4 in tissues of the human female reproductive tract. Infect. Immun. 72, 5799-5806.

Reece, J. C., Handley, A. J., Anstee, E. J., Morrison, W. A., Crowe, S. M., and Cameron, P. U. (1998). HIV-1 selection by epidermal dendritic cells during transmission across human skin. J. Exp. Med. 187, 1623-1631.

Ribeiro Dos Santos, P., Rancez, M., Pretet, J. L., Michel-Salzat, A., Messent, V., Bogdanova, A., Couedel-Courteille, A., Souil, E., Cheynier, R., and Butor, C. (2011). Rapid dissemination of SIV follows multisite entry after recta inoculation. PLOS ONE 6, e19493. doi:10.1371/journal.pone.0019493

Robinson, M. J., Sancho, D., Slack, E. C., Leibundgut-Landmann, S., and Reis E Sousa, C. (2006). Myeloid Ctype lectins in innate immunity. Nat. Immunol. 7, 1258-1265.

Romani, N., Clausen, B. E., and Stoitzner, P. (2010). Langerhans cells and more: Langerin-expressing dendritic cell subsets in the skin. Immunol. Rev. 234, 120-141.

Saphire, A. C., Bobardt, M. D., Zhang, Z., David, G., and Gallay, P. A. (2001). Syndecans serve as attachment receptors for human immunodeficiency virus type 1 on macrophages. J. Virol. 75 9187-9200.

Sharova, N., Swingler, C., Sharkey, M., and Stevenson, M. (2005). Macrophages archive HIV-1 virions for dissemination in trans. $E M B O J$. 24, 2481-2489.

Sina, S. T., Ren, W., and Cheng-Mayer C. (2010). Coreceptor use in nonhuman primate models of HIV infection. J. Transl. Med. 9(Suppl. 1), S7.

Sivard, P., Berlier, W., Picard, B., Sabido, O., Genin, C., and Misery, L. (2004) HIV-1 infection of Langerhans cells in a reconstructed vaginal mucosa. $J$. Infect. Dis. 190, 227-235.

Smed-Sorensen, A., Lore, K., WaltherJallow, L., Andersson, J., and Spetz, A. L. (2004). HIV-1-infected dendritic cells up-regulate cell surface markers but fail to produce IL-12 p70 in response to
CD40 ligand stimulation. Blood 104, 2810-2817.

Smith, A. L., Ganesh, L., Leung, K., Jongstra-Bilen, J., Jongstra, J., and Nabel, G. J. (2007). Leukocytespecific protein 1 interacts with DCSIGN and mediates transport of HIV to the proteasome in dendritic cells. J. Exp. Med. 204, 421-430.

Spira, A. I., Marx, P. A., Patterson, B. K., Mahoney, J., Koup, R. A., Wolinsky, S. M., and Ho, D. D. (1996). Cellular targets of infection and route of viral dissemination after an intravaginal inoculation of simian immunodeficiency virus into rhesus macaques. J. Exp. Med. 183, 215-225.

Stremlau, M., Owens, C. M., Perron, M. J., Kiessling, M., Autissier, P., and Sodroski, J. (2004). The cytoplasmic body component TRIM5alpha restricts HIV-1 infection in Old World monkeys. Nature 427, 848-853.

Stremlau, M., Perron, M., Lee, M., Li, Y., Song, B., Javanbakht, H., Diaz-Griffero, F., Anderson, D. J., Sundquist, W. I., and Sodroski, J. (2006). Specific recognition and accelerated uncoating of retroviral capsids by the TRIM5alpha restriction factor. Proc. Natl. Acad. Sci. U.S.A. 103, 5514-5519.

Thibault, S., Fromentin, R., Tardif, M. R., and Tremblay, M. J. (2009). TLR2 and TLR4 triggering exerts contrasting effects with regard to HIV-1 infection of human dendritic cells and subsequent virus transfer to CD4+ T cells. Retrovirology 6, 42 .

Trombetta, E. S., and Mellman, I. (2005). Cell biology of antigen processing in vitro and in vivo. Annu. Rev. Immunol. 23, 975-1028.

Trujillo, J. R., Rogers, R., Molina, R. M., Dangond, F., Mclane, M. F., Essex, M., and Brain, J. D. (2007). Noninfectious entry of HIV-1 into peripheral and brain macrophages mediated by the mannose receptor. Proc. Natl. Acad. Sci. U.S.A. 104, 5097-5102.

Turville, S. G., Arthos, J., Donald, K. M., Lynch, G., Naif, H., Clark, G., Hart, D., and Cunningham, A. L. (2001). HIV gp120 receptors on human dendritic cells. Blood 98, 2482-2488.

Turville, S. G., Cameron, P. U., Handley, A., Lin, G., Pohlmann, S., Doms, R. W., and Cunningham, A. L. (2002). Diversity of receptors binding HIV on dendritic cell subsets. Nat. Immunol. 3, 975-983.

Turville, S. G., Santos, J. J., Frank, I., Cameron, P. U., Wilkinson, J., Miranda-Saksena, M., Dable, J. Stossel, H., Romani, N., Piatak, M. 
Jr., Lifson, J. D., Pope, M., and Cunningham, A. L. (2004). Immunodeficiency virus uptake, turnover, and 2-phase transfer in human dendritic cells. Blood 103, 2170-2179.

UNAIDS. (2010). Getting to Zero, UNAIDS Strategy Report 2011-2015. WHO Library, Geneva.

Valladeau, J., Duvert-Frances, V., Pin, J. J., Dezutter-Dambuyant, C., Vincent, C., Massacrier, C., Vincent, J., Yoneda, K., Banchereau, J., Caux, C., Davoust, J., and Saeland, S. (1999). The monoclonal antibody DCGM4 recognizes Langerin, a protein specific of Langerhans cells, and is rapidly internalized from the cell surface. Eur. J. Immunol. 29, 2695-2704.

van der Aar, A. M., Sylva-Steenland, R. M., Bos, J. D., Kapsenberg, M. L., De Jong, E. C., and Teunissen, M. B. (2007). Loss of TLR2, TLR4, and TLR5 on Langerhans cells abolishes bacterial recognition. J. Immunol. 178, 1986-1990.

van der Vlist, M., Van Der Aar, A. M., Gringhuis, S. I., and Geijtenbeek, T. B. (2011). Innate signaling in HIV-1 infection of dendritic cells. Curr.
Opin. HIV AIDS 6, 348-352.

Van Rompay, K. K. (2012). The use of nonhuman primate models of HIV infection for the evaluation of antiviral strategies. AIDS Res. Hum. Retroviruses 28, 16-35.

Veazey, R. S., Marx, P. A., and Lackner, A. A. (2003). Vaginal CD4+ T cells express high levels of CCR5 and are rapidly depleted in simian immunodeficiency virus infection. J. Infect. Dis. 187, 769-776.

Villadangos, J. A., and Heath, W. R. (2005). Life cycle, migration and antigen presenting functions of spleen and lymph node dendritic cells: limitations of the Langerhans cells paradigm. Semin. Immunol. 17, 262-272.

von Bubnoff, D., Bausinger, H., Matz, H., Koch, S., Hacker, G., Takikawa, O., Bieber, T., Hanau, D., and De La Salle, H. (2004). Human epidermal langerhans cells express the immunoregulatory enzyme indoleamine 2,3-dioxygenase. J. Invest. Dermatol. 123, 298-304.

Wang, X., Chao, W., Saini, M., and Potash, M. J. (2011). A common path to innate immunity to HIV1 induced by Toll-like receptor ligands in primary human macrophages. PLoS ONE 6, e24193. doi:10.1371/journal.pone.0024193

Wiley, R. D., and Gummuluru, S. (2006). Immature dendritic cellderived exosomes can mediate HIV1 trans infection. Proc. Natl. Acad. Sci. U.S.A. 103, 738-743.

Yu, H. J., Reuter, M. A., and Mcdonald, D. (2008). HIV traffics through a specialized, surface-accessible intracellular compartment during transinfection of $\mathrm{T}$ cells by mature dendritic cells. PLoS Pathog. 4, e1000134. doi:10.1371/journal.ppat. 1000134

Zhang, J., Li, G., Bafica, A., Pantelic, M., Zhang, P., Broxmeyer, H., Liu, Y., Wetzler, L., He, J. J., and Chen, T. (2005). Neisseria gonorrhoeae enhances infection of dendritic cells by HIV type 1. J. Immunol. 174, 7995-8002.

Zhang, Y., Nakata, K., Weiden, M., and Rom, W. N. (1995). Mycobacterium tuberculosis enhances human immunodeficiency virus-1 replication by transcriptional activation at the long terminal repeat. J. Clin. Invest. 95, 2324-2331.

Conflict of Interest Statement: The authors declare that the research was conducted in the absence of any commercial or financial relationships that could be construed as a potential conflict of interest.

Received: 20 December 2011; paper pending published: 31 January 2012; accepted: 07 March 2012; published online: 26 March 2012.

Citation: Mesman AW and Geijtenbeek TB (2012) Pattern recognition receptors in HIV transmission. Front. Immun. 3:59. doi: 10.3389/fimmu.2012.00059

This article was submitted to Frontiers in HIV and AIDS, a specialty of Frontiers in Immunology.

Copyright (C) 2012 Mesman and Geijtenbeek. This is an open-access article distributed under the terms of the Creative Commons Attribution Non Commercial License, which permits noncommercial use, distribution, and reproduction in other forums, provided the original authors and source are credited. 